\title{
Bayesian Model for Covid-19 to Achieve Immunity by Parsimony of Exponential Functions Minimizing the Inoculum
}

\author{
Nery Lamothe ${ }^{1}$, Mara Lamothe ${ }^{1}$, Daniel Lamothe ${ }^{2}$, Carlos Sierra ${ }^{3}$, Cinthya Harumi González- Téllez-Girón ${ }^{4}$, Victor Hugo Rodas ${ }^{4}$, \\ Alejandro Lamothe ${ }^{5}$, Jorge Sanchez-Montiel ${ }^{6}$, Carlos Lamothe ${ }^{7}$, Humberto Galicia ${ }^{8}$, Jose Luis Perez-Avalos ${ }^{9}$, Octavio Rojas $^{10}$, \\ Zoraida Cazarin $^{11}$, Anna Valeria de la Peña ${ }^{12}$, Alicia Diaz-del Bosque ${ }^{13}$, and Pedro J. Lamothe ${ }^{14 *}$
}

${ }^{1}$ Universidad Autónoma Metropolitana, División de Ciencias de la Salud, Carrera de Médico Cirujano, Mexico

${ }^{2}$ Universidad Westhill, Escuela de Medicina, Mexico

${ }^{3}$ Jefe de Enseñanza, Instituto Nacional de Cardiología, Ignacio Chavez, Mexico

${ }^{4}$ Former Lecturer in Human Rights, Mexico

${ }^{5}$ President IQ Dimensions, Mexico

${ }^{6}$ Former Director Division Ciencias de la Salud. Instituto Tecnologico y de Estudios Superiores de Monterrey, Campos Ciudad de México

${ }^{7}$ Vicerrector de la Region Coatzacoalcos Minatitlan, Universidad Veracruzana, Mexico

${ }^{8}$ Former Director of the Universidad Westhill, Escuela de Medicina, Mexico

${ }^{9}$ Coordinator of the Medical Surgeon Career, División de Ciencias Biologicas y de la Salud, Universidad Autónoma Metropolitana, Mexico

${ }^{10}$ The American British Cowdray Medical Center, Surgery Division, Fellow of the American College of Surgeons, Mexico

${ }^{11}$ Hospital “Darío Fernández Fierro" ISSSTE. General Surgery Service, Mexico

${ }^{12}$ Universidad Anahuac, Escuela de Medicina, Mexico

${ }^{13}$ Intensive Care Unit, Hospital 20 de Noviembre. ISSSTE, Mexico

${ }^{14}$ Instituto de Genética, Metabolismo y Reproducción, Prolaif S.C. Primer Mandante Epistemócrata de los Estados Unidos Mexicanos, ONG, Mexico

*Corresponding author: Pedro J. Lamothe, Instituto de Genética, Metabolismo y Reproducción, Prolaif S.C Primer Mandante Epistemócrata de los Estados Unidos Mexicanos, A.C.O.N.G, Mexico, Email: plamothe@lamothe.com

Received: 06 Dec, 2020 | Accepted: 20 Jan, 2021 | Published: 27 Jan, 2021

Citation: Lamothe N, Lamothe M, Lamothe D, Sierra C, González- Téllez-Girón CH, et al. (2021) Bayesian Model for Covid-19 to Achieve Immunity by Parsimony of Exponential Functions Minimizing the Inoculum. J Emerg Dis Virol 6(1): dx.doi.org/10.16966/2473-1846.160

Copyright: (C) 2021 Lamothe N, et al. This is an open-access article distributed under the terms of the Creative Commons Attribution License, which permits unrestricted use, distribution, and reproduction in any medium, provided the original author and source are credited.

\section{Abstract}

A ribonucleoside analog MK-4482/EIDD-2801 blocks SARS-CoV-2 transmission in ferrets and might be able to diminish transmission until vaccineinduced or naturally acquired protective herd immunity is reached [1]. As skinner pointed out, behavioral problems have to be solved through behavioral engineering [2]. Cybernetics has full application in the present condition. As in alcohol consumption, smoking, drugs, gun crimes, wars, and sexually acquired diseases, the teleological Aristotelian causes are not tobacco, drugs, and any other issue, but the aberrant behavior. The situation is not trivial and involves non-classic logic and other mathematical logics [3,4]. The neural topography corresponds to the nucleus accumbens. The latter is the battlefield, and the subject's obsession is the rise of the neurotransmitter dopamine [3,4]. In general, people are very demanding from their governments; nevertheless, at the same time, they are deeply tolerant with their aberrant behavior promoting the dissemination of the SARSCoV-2 $[4,5]$. This paper examines how to deal with this problem from a scientific perspective, considering probability methods and classical and doxastic logic, using the Parsimony Principle aiming to reach immunity by minimizing the inoculum.

Keywords: Covid-19; Herd immunity; Behavioral engineering; Inoculum; Variolation; Control pandemic; Probabilistic methods; Intelligent methods; Doxastic logic; Bayes theorem

\section{Introduction}

Many researchers think that the crucial question for controlling and managing a Covid-19 pandemic is: What is the probability that a patient with a specific set of symptoms or signs has Covid? [6,7].

However, in congruency with Bayes methods the absolutely essential questions to control the pandemic in their territory are:

- What are the enforceable policies that a government and decision-makers of medical resources should demand from the inhabitants?
- What are the specific actions to minimize or eradicate the Covid Pandemic?

The last questions are related to multidisciplinary areas, mainly: Aristotelian, Modal and Doxastic logic for analyzing the belief of citizens and different groups of the country, and also for determining how to handle aberrant behavior of people, media, and government. Virology and immunology behavioral engineering economics; Bayes methods for evaluating the probability of different scenarios; combinatorics, optimization, machine learning, and deep learning, and several artificial intelligence areas to evaluate and estimate different scenarios, and deep learning of medical advances in the field. 
Nevertheless, most of the articles about the Covid-19 do not consider the real problem related to the last issues, but only how to measure the phenomenon, describe the situations, or present medical advances, such as new procedures or vaccines.

The present article deals with these issues, aiming to determine the best measures for controlling the pandemic. The paper takes part from scenarios with exponential functions of new confirmed patient; then analyses the action to change the latter function from a very exponential form to a weakly exponential or even a polynomial function. Finally, we present the efficient policy around the world by the simple expedient of behavioral modification to diminish the amount of the inoculum and control the pandemic.

\section{Probability Methods}

Instead, to calculate the probability that a patient with a particular sign or symptom has COVID-19. To do that, let us consider the next question:

Which is the probability that a patient with COVID-19 has a specific symptom or sign $D_{\mathrm{e}}$ ?

Let us now consider the next set $\Delta=\left\{\mathrm{D}_{\mathrm{e}}\right.$ : eeJ $\}$ that is any class of mutually exclusive countable events, such that:

$\mathrm{D}_{\mathrm{e}}=$ The Disease with all its features associated

$\mathrm{A}=\mathrm{Abnormal}$ result in the test

$\mathrm{D}_{\mathrm{j}}=$ No disease

$\mathrm{P}(\bullet)=$ The Bayesian Probability Function

If $\mathrm{A}$ is an abnormal test where the Covid-19 test result is positive, then this situation's probability is measured with equation 1 .

$$
P\left(D_{e} / A\right)=\frac{P\left(A / D_{e}\right) \mathrm{P}\left(\mathrm{D}_{e}\right)}{\mathrm{P}(\mathrm{A})}=\frac{P\left(A / D_{e}\right) \mathrm{P}\left(\mathrm{D}_{e}\right)}{\sum_{j \in J} P\left(A / D_{j}\right) P\left(\mathrm{D}_{j}\right)}
$$

Nevertheless, it is well known that the evolution of an epidemic can be modeled with the deterministic differential equations (2),(3),(4) developed by Kermack and McKendrick [8].

$$
\begin{aligned}
& \frac{d S}{d t}=-\beta(t) I(t) \frac{S(t)}{N} ; \mathrm{S}(0)=\mathrm{S}_{0} \geq 0 \\
& \frac{d I(t)}{d t}=\beta I(t) \frac{S(t)}{N}-\gamma(t) I(t) ; I(0)=I_{0} \geq 0 \\
& \frac{d R(t)}{d t}=-\gamma(t) I(t) ; R(0)=R_{0} \geq 0
\end{aligned}
$$

\section{Where:}

$\mathrm{S}(\mathrm{t})$ : Number of individual not infected but susceptible to being infected at time $(\mathrm{t})$

$\mathrm{I}(\mathrm{t})$ : Number of individuals infected at the time $(\mathrm{t})$ or iteration $(\mathrm{k})$

$R(t)$ : Number of individuals previously infected that never will be infected again (they are immune or dead).

The last variables S, I, R fulfills the Equation (5), where $\mathrm{N}$ is the population size:

$$
N(t)=S(t)+I(t)+R(t)------5
$$

There are several properties of these equations that we will not discuss in detail. For the moment, we can obtain stochastic differential equations only by changing $\mathrm{I}, \mathrm{S}$, and $\mathrm{R}$ in a stochastic variable with the distribution of each of them by a simple sample of previous cases. The significant advantage of that transformation is that we can apply modern stochastic methods to predict and control these kinds of variables $[4,5]$.

Nonetheless, politicians, media communicators, and citizens genuinely concerned about COVID-19, should understand the last equations model for people in charge of handling a situation that can lead to the loss of the lives of millions of people. It is imprescindible to cogitate, rather than just understand, the paradigmatic compartment model of Kermack and McKendrick [8].

Depending on the nature of the parameters and variables, these equations can be stochastics or deterministic. The second type is the most simple, and the equations only approximate the World's real stochastic performance. However, they are not always entirely useless powerful stochastic modeling can take them as part of it. Also, from this case, we can determine useful properties for pandemic control. Firstly note that the value of variable $\mathrm{N}$ in equation does not change a lot in a short period. Then, $\mathrm{N}$ can be handled as a constant, and $\mathrm{dN} /$ $\mathrm{dt}$ is zero. Thus, it is clear that the sum of the three compartmental differential equations is equal to zero, and equation (6) is obtained:

$$
\frac{d S}{d t}+\frac{d I}{d t}+\frac{d R}{d t}=-\beta S I+\beta S I-y I+y I=0
$$

Here we have the paradigmatic classical model by which 6 the growth rate of the pandemic can be estimated. It is based on three factors: the susceptibility of people (S) to be infected, the rate at which infections occur de facto (infectivity), and the infection rate. The resistance includes those who recover and those who die. This is what constitutes the SIR model, which corresponds to the simultaneous solution of the three differential equations, as described in 1927 by W. O. Kermack and A. G. McKendrick [8].

$$
\begin{aligned}
& \frac{d y}{d t}=\beta x y-\gamma y^{------4(b)} \\
& \frac{d z}{d t}=-\gamma y^{-----4(c)}
\end{aligned}
$$$$
\text { Defining } x(\mathrm{t})=\frac{S(t)}{N} ; y(t)=\frac{I(t)}{N} ; z(t)=\frac{R(t)}{N}
$$$$
\text { We have the next equations system: } \frac{d x}{d t}=-\beta x y ; x(0)=\frac{N(0)}{S(0)}-----4(\mathrm{a})
$$

Because for the initial condition, all the population is susceptible to being infected, $\mathrm{x}(0)$ is equal to one; thus, we can solve equations (4) using simple methods. For instance, taking equations (4b) and (4c):

$$
\begin{aligned}
\frac{d y}{y} & =(\beta x-\gamma) t ; \text { then } y=K e^{(\beta x-\gamma) t} \\
d z & =\gamma y d t \text {------ (6) }
\end{aligned}
$$

A discrete model can be obtained for each variable. For instance, from equation (6) we obtained:

$$
z(t+1)=z(t)-\gamma y(t)+\varphi(\mathrm{t})
$$

Where $\varphi(t)$ represents the residuals in the estimation of the stochastic method's error during a learning phase of it.

In the SIR model, the basic reproduction number R0 is defined as the number of cases that we expect to occur. On average, in a 
homogeneous population, as a product of the infection provoked by a single contagious person, when the whole population is susceptible at the beginning of an epidemic before immunity starts to develop and before any attempt at immunization has been made. So, if a single patient infects two others, then the $\mathrm{R}_{0}$ is 2 [8]. When the average $\mathrm{R} 0$ in the population is greater than one, the infection will be disseminated according to the logistic function that initially grows exponentially. This model is tragically described obeying the following differential equation:

$$
\frac{d N}{d t}=r N\left(1-\frac{N}{K}\right)
$$

In equation (7), $\mathrm{N}$ is the population size, $\mathrm{K}$ is the number of inhabitants supported by the environment, and $\mathrm{r}$ is population growth. From this equation, we can obtain the next relations [8]:

$$
\frac{d N}{d t}=-\frac{r}{K} N(N-K)
$$

Then

$$
\frac{1}{N(N-K)} d N=-\frac{r}{K} d t
$$

The equation can be solved as follows:

$$
\frac{1}{N(N-K)} d N=-\frac{r}{K} d t
$$

We integrate both sides of the equation (10) and finding the $\mathrm{N}$ expression given by equation (11)

$$
N(t)=\frac{-K C e^{r t}}{1-C e^{r t}}=\frac{K C}{C-e^{-r t}}=N(t)=\frac{K}{1-\frac{e^{-r t}}{C}}
$$

As we mentioned before, when $\mathrm{t}=0, \mathrm{~N}(0)=\mathrm{S}(0)=\mathrm{K}$. Then the $\mathrm{C}$ parameter in equation (11) is given by $C=\frac{N_{0}}{N_{0}-K}$; then we obtain the equation (12)

$$
N(t)=\frac{K}{1+\left(\frac{N_{0}-K}{N_{0}}-1\right) e^{-r t}}=\frac{K}{1+\left(\frac{K}{N_{0}}-1\right) e^{-r t}}
$$

Thus, applying the right policies using a model like this can decrease the number of variables related to the number of affected people by the pandemic. We define a policy as a set of actions applied to achieve an objective. In general, the optimal police set are not the same in every period of time. Thus, a specific method should be designed for that.

When political correctness implies accepting false data, axioms, premises, or protocol clauses and apodictically generating fallacious conclusions, then politically correctness consists in being against logic, mathematics, and the advances of science. It means incorporating hypostases rather than hypothesis, that everyone talks about but, no one has ever demonstrated.

We can scientifically study everything, including beliefs (doxa), religion, free will, unconsciousness, qualia, and so on, which is absolutely different from accepting that they are real. All the mentioned ones are incompatible conditions with current scientific paradigms, in the same way as schizophrenia; the procedure is not beginning with the premise that hallucinations correspond to reality; however, it is the case that the patients have them. It is real the existence of the belief even though what is believed is non-existent.

A goal to acquire herd immunity with the lowest mortality has been historically reached through vaccination. However, many naive proponents have the wishful thinking of strategies to reach herd immunity with low mortality.

Typically, viral vaccines are classified into attenuated live viruses, killed viruses, and viral fragments. Notwithstanding, there are alternative ways to acquire immunity, which are not a product of the genius's mind. They are the product of natural selection which, by itself, is a tragedy even though every living being is a product of it. There exists an exception, a type of molecular anagnorisis, which is mathematically catastrophic: variolation [10].

It is well known that the differential equations of the Kermack and McKendrick model and its variants constitute the foundations upon which every epidemiological proposal related to the SARS-Cov-2 Pandemic has to be made. In the same manner as the Kermack and McKendrick differential equations, the probabilitarian and Bayesian calculations have to be rigorous, as well as the biomolecular, virological, immunological, and biophysical considerations.

Biophysical considerations predict the behavior of the virus after the release from the infected cell, its expulsion, its dispersion and its trajectory in the environment, its intraluminal behavior in the susceptible person, and its interaction with the molecular receptor [11].

It is our straightforward theoretical approach to utilize the wild and unmodified SARS-CoV-2 in order to produce immunity by the simple expedient of decrease the amount of the inoculum to the minimum minimorum.

It is the purpose of this work to give evidence to the scientific community in a systems theory approach, that there is solid scientific knowledge available to tame the pandemic, which is mainly a behavioral problem that requires cybernetics through behavioral engineering [2,12].

Although everybody is having a naïve expectative about the SARS$\mathrm{CoV}-2$ vaccine, a conundrum we face and we have to decide: With the shortage of vaccines, what is going to be the assignation policy? We have to recognize that once we have reached this circumstance, the decision is going to be a violation of human rights. We are not going to have enough vaccines; certainly, not at the beginning. Who gets the best vaccine? Other that could be taken are: First in time then first in right (queue); assignation by age; applying to those who need the most (ad Lazarus fallacy); to the most needed subjects for the society (those who we need the most); To those who pay more (free market); random aleatory, a type of lottery; will it be decided through a plebiscite; first the old people, women, and children; first the workforce; First the most exposed; first, those to which the population is most exposed (the supermarket cashier for example).

Regarding the economic policies to be enforced to provide protection according to priority for sectors of the market that are important like tobacco, alcohol beverages, bars, beauty parlors, fast food, casinos; they might be important from the economical point of view, however what they produce is far from essential for the population, on the contrary, per se, they are mostly deleterious.

Facing the scarcity of the vaccine and by a diversity of qualities, there will be a decision algorithm with which no one will agree, because 
those who want the vaccine, want it even if they do not deserve it, even if they are not the ones who need it the most, although they are not the ones who contribute the most to society, even if they do not have the right to have it. This is a imminent in spite of no one recognizing it, since the existence of reality is not subject to a doxastic logic nor to a desiderative logic. The existence of the conflict is conditionally subject to a process of ochlocratic suffrage [4].

A new article, genome wide association study of severe Covid-19 with respiratory failure published in The New England Journal of Medicine obligate scientist, politicians, media commentators, and the public at large to be aware that some, due to genetic reasons, are at greater risk of having a serious clinical picture if they become infected. This fact immediately generates an unescapable violation of human rights due to discrimination. If these people are given preference, then they are discriminated against those who do not have the gene and if it is not given to them then they are discriminated punishing them for genetic reasons [13]. However, Ad impossibilia nemo tenetur.

From a human rights perspective, access to vaccination is a component of the right to the highest attainable standard of health. General comment No. 14 of The Committee on Economic, Social and Cultural Rights of the United Nations (CDESC) (CDESC, 2000) even recognizes the existence of the right to prevention and treatment of diseases, which translates into the obligation, for the national states, to have a system of urgent medical attention in cases of epidemics and similar dangers to health, as well as the execution or expansion of vaccination programs and other strategies to combat infectious diseases.

In principle, access to vaccines should be guaranteed on a nondiscriminatory basis, to ensure that it benefits the population with the greatest risk of vulnerability; Hence, the refusal of a State to vaccinate the members of a community against serious infectious diseases may constitute a violation of the right to health, even if this refusal is intended to be based on situations such as national security or the maintenance of order public.

Therefore, according to the ESCR Committee, any state measure that implies a restriction on access to treatment, and specifically to vaccines, must be consistent with national and international standards for the protection of human rights; pursue a legitimate purpose and be strictly necessary to promote the general welfare in a democratic society (CDESC, 2000). In the case of vaccines against COVID-19, it is understandable that, as long as enough doses are produced or acquired to achieve national coverage, states are forced to develop plans that prioritize access to these for certain groups of the population; however, this decision should not be alien to the human rights approach, since it requires carrying out an exercise of analysis and weighting that transcends the epidemiological sphere, to consider social and economic factors of the different sectors.

The World Health Organization (WHO) published on September 14,2020 , the document framework of values for the assignment and prioritization of COVID-19 vaccination (World Health Organization, 2020), in which it is established that the priority groups for vaccination may include, among other groups, essential workers - including frontline health personnel-and older people; however, it also indicates that the prioritization scheme of each State must be complemented with information on the specific characteristics of the vaccine (s); the evaluation of the risk-benefit for different population groups; the quantity and rate of vaccine supply; the epidemiological, clinical, economic management, and the social impact of the pandemic.
The manual identifies as priority groups, people with comorbidities, those whose social conditions aggravate pre-existing health conditions, population groups not based on age with a significantly high risk of infection and transmission; groups living in multigenerational households, school-age girls, boys and adolescents, people living in extreme poverty; in a situation of vulnerability for reasons of ethnic, racial, gender discrimination, religious groups, genders preferences and people living with disabilities.

WHO recommends that national vaccination plans consider the protection and promotion of human well-being in all its dimensions and not only from a health perspective; that is, considering the social and economic spheres, security, human rights, and civil liberties, and the integral development of minors.

From our perspective, the immunization plan must consider respecting the interests of all individuals and groups with equal consideration in decisions to prioritize vaccination, and ensure that the vulnerabilities, the risks, and the needs of groups that are affected are taken into consideration, due to underlying social, geographic or biomedical factors, they are at risk of greater burdens from the COVID-19 pandemic.

Whenever $\mathrm{R}_{0}$ is less than one, the infection will progress slowly and then disappear. The higher the value of $\mathrm{R}_{0}$ the faster the epidemic will grow. The value of $\mathrm{R}_{0}$ is calculated from the data obtained in the field, in other populations, or at other times and then, incorporated into the mathematical models.

If the test has a sensitivity of $99 \%$ but a large number of patients are deliberatively not tested and are mistakenly considered negative, they are in reality false negatives. Thus, false negatives are all those who, in spite of being ill, were not identified as such in the test, plus those who, being ill, were not tested and are wrongly reported as negative [4].

At present, that more tests are performed, the number of positives increases and the reason is double; On the one hand, patients previously required by some states, to stay at home, unless they were gravely ill, are being subjected to the tests and, sadly due to ignorance of Bayes' theorem and the effect of false positives [4].

The doxastic fascination for the so-called herd immunity provokes a reckless, suicidal, and harmful social response against others. The proponents fallaciously assume that if the virus is allowed to spread in a controlled manner, the population will acquire sufficient immunity and spread will be prevented.

The tragedy if we allow people to become infected spontaneously or worse, deliberately attempting herd immunity, is that it has the lethal effect that a high percentage will necessarily die. This percentage is the fatality rate. Image a hypothetically viral disease that no person has acquired in the world. To do the exercise in a dramatic way, for all critics, with elementary arithmetic: If $\mathrm{R}_{0}=1$ or less and the incubation time is one week, 52 will be infected in one year. If $\mathrm{R}_{0}=2$, then will be infected, approximately $1,000(1,024)$, in 10 weeks and in 20 weeks approximately $1,000,000$ will be infected and in 30 weeks approximately $1,000,000,000$ will be infected.

$$
\text { Since: } \frac{R_{0}-1}{R_{0}}=1-\frac{1}{R_{0}}=R_{0}\left(1-\frac{1}{R_{0}}\right)
$$

In order to prevent the spread of infection, the proportion of the population that has to acquire immunity $\left(\mathrm{P}_{\mathrm{i}}\right)$ has to be greater than $\left(\mathrm{R}_{0}-1\right) / \mathrm{R}_{0}$. For example, if $\mathrm{R}_{0}=2$, then immunization needs to reach $(2-1) / 2=50 \%$ of the population; however, if $\mathrm{R}_{0}=5$, the proportion skyrockets to require $(5-1) / 5=80 \%$ to be immune. Beyond this, an 
increase in $\mathrm{R}_{0}$ of 10 increases the need to acquire an immunization of $(10-1) / 10=90 \%$. For example, measles has an $R_{0}$ that is greater than 10 , for which it is required to immunize practically the entire population.

Consequently, if $\mathrm{R}_{0}$ is 10 , an infant with measles will infect on average ten healthy children if they are susceptible. Le us suppose that other children have already been infected. Thus, obviously, he or she would not be able to infect those who have died. Besides these children could not infect those who have recovered. When the population's immunity has reached $90 \%$ or more, the probability of interacting with an unimmunized susceptible will tend to zero and the population will be immune, but having paid with a death toll that the affected tragically cannot claim, which is the fatality rate.

Consequently, at any time, $R_{e}=R_{0}\left(1-P_{i}\right)$, where $P_{i}$, is the proportion of the population that has become immune at that moment.

These are the rigorous methods that involve the mathematical calculation of the value of $\mathrm{R}_{0}$, which constitute the paradigm.

The sensitivity depends, among many other variables, on the time elapsed between the exposure and the performance of the test.

We can, hypothetically consider the prevalence of positivity in the RT-PCR test. A virus can have a high fatality rate, but very low contagion capacity. On the other hand, it can have a low fatality rate but be extremely contagious. It is not only essential to calculate the probability of an outcome. It is much more transcendent to calculate the consequence of one result or the other. In the mathematical game of the model of the russian roulette, the probability that the bullet kills the player is $1 / 5$, which means that the probability that nothing happens is $4 / 5$; that is, $80 \%$ probability of a favorable outcome; notwithstanding, $20 \%$ of those who compute in this way end up dead. What is even worse, those who win the first time might feel, by pure superstition, good prognosticators and ready to repeat the bet until the bullet kills them.

Deeply relevant is the case of poliomyelitis. It is dramatically illustrative in which we must separate the concept of infection from the concept of the sequel, which, according to the World Health Organization, the vast majority of poliovirus infections do not produce symptoms, but 5 to 10 out of 100 people infected with the polio virus might have some flulike symptoms; however, 1 in 200 cases, the virus destroys alpha moto neurons, causing permanent paralysis in the legs or arms. 30 years ago, polio paralyzed nearly 1,000 children every day [14].

The legislators and policymakers must be thoroughly aware that vaccines might not be as efficient as desired and may also have unexpected grave side effects.

At the end of November 2020, there are about 1,500,000 deaths in the whole world attributable to COVID-19 and 63 millions of recognized cases [15].

It is absolutely imperative to recognize that the ignorance of the concept of exponential growth has been considered the most extreme intellectual shortcoming in history [16-24].

Gedanken experiment, (German: "thought experiment") is a expression by Albert Einstein to express his approach of using conceptual instead actual experiments in order to generate the theory of relativity [25]. Theoretically, the desiderata of our minimum minimorum approach would be to directly expose the minimum number of respiratory epithelial cells to the minimum number of viral particles of the wild SARS-Cov-2. In this hypothetical hyperbolic scenario, the successful reproduction of the virus will induce a robust immunological response. This response should be a parsimonious one i.e. not an overwhelming response. It will be in such a manner that the immune system will be able to mount an exponential response timely, which strictly will be superior to the exponential replication of the virus. If this can be achieved, we would have acquired, not just an immunological solution against $S A R S-C o V-2$, but against many past, present, and future pathogens, like HIV, Syphilis, etc.

There are some patients who are HIV controllers [26]. Even Though It is not known if those patients considered tolerant to HIV are, in fact, cases produced by the primary exposure to a minimum minimorum inoculum, which would be consistent with our working hypothesis.

Nobody knows why the immunological response of a patient infected with 1,000 viral particles is different than that of a person infected with just one particle? The answer, we maintain, as expected from the argumenta, the exponential growth [17-24].

The result corresponds to the exponential functions. If we suppose a hypothetical virus, such that, once it is inside the cytoplasm of the cell, it can replicate in one hour, so we will have 2 viral particles. After 2 hour, there will be 4 particles, after 3 there will be 8 particles, and so on. If we continue for 10 hours, we will have approximately 1,000 viral particles $(1,024)$, and in 20 hours, $1,000,000$ particles.

The target is that the exponential function of antibody production and the exponential function of T-cell activation be over whelming to the exponential function of the virus reproduction.

If we conceptulize a healthy subject who gets in contact with a patient with coronavirus, in such a way that when this subject gets infected, it happens not with one particle, but with 1,000 . If a person is infected with 1,000 viral particles, these can get replicated in one hour, so there is going to be 2,000 viral particles after 1 hour, after two hours there will be 4,000 particles, After 3 hours there will be 8,000 particles, and so on. If we continue, iteratively, for 10 hours, we will have approximately 1,000,000 viral particles and in 20 hours, $1,000,000,000$ viral particles.

In the case of the exponential growth, the immunological response outgrows the exponential growth of the virus replication, we would have not just reached immunization, but we would have the solution to the Pandemic and of many that will follow.

We want to physically contextualize mathematically as a matter of competence between two exponential functions. On one hand, the exponential reproduction of the virus, and on the other hand, the exponential production of the antibodies and of the activation of $\mathrm{T}$ cells. We should minimize the amount of the inoculum, to the extreme of minimum minimorum, able of infecting the minimum susceptible cell subpopulation in a susceptible subject.

Wearing masks and contagion are intuitively described as a discrete phenomenon, even more so, a Boolean concept, when in reality it is a continuous one, at least, relatively to the amount of inoculum. No two susceptible persons receive the same amount of inoculum, neither have they responded in the same manner.

In mathematically game theory, the key problem would be, how to deliver the antigen, in order to generate the immune response in the susceptible; that is, to an algorithm to get the minimum viral inoculum. In the article by Gandhi and Cols. and later in Perspective in NEJM [27], they definitively found the solution to the viral delivery problem. They insisted in that the use of masks should diminish the inoculum and produce a less severe clinical picture. They described it educatively as variolation [10]. 
The use of masks, implemented universally, would produce the aimed effect of diminishing the inoculum and, we hypothesized, in turn, the parsimony of the exponential viral growth relative to the exponential growth of the immune response.

A fundamental consideration is to be cognitive that the amount of inoculum decays with the square of the distance between an infective patient and the susceptible. In this regard, it is most illustrative: Exploring the effect of inoculum dose on host immunity and morbidity to inform model-based vaccine design [28].

A new publication, vinculated to this topic to be judged, contrasting against our hypothesis: The Great Barrington Declaration which is clearly opposite to scientific knowledge [29].

The principal idea of the Great Barrington Declaration, absolutely all of which is, at least, logically fallacious, and also against human rights are:

"The current lockdown policies are producing tragic effects. Maintaining students out of school is a grave injustice. We know that all populations will eventually reach herd immunity. The most compassionate approach that balances the risks and benefits of reaching herd immunity, is to allow those who are at minimal risk of death to live their lives normally to build up immunity to the virus through natural infection, while better protecting those who are at highest risk remain at home. Those who are not vulnerable, should immediately be allowed to resume life as normal. Schools and universities should be open to in-person teaching. Extracurricular activities, such as sports, should be resumed. Young low-risk adults should work normally, rather than from home. Restaurants and other businesses should open. Arts, music, sport, and other cultural activities should resume. People who are more at risk may participate if they wish, while society as a whole enjoys the protection conferred upon the vulnerable by those who have built up herd immunity." On October 4, 2020, Great Barrington, United States, We epistemological and axiologically endorse The John Snow Memorandum [30].

The publication of the Great Barrington Declaration is a tragic instance. Even though, our definitively recommended approach would improve the expected result of a policy that could, wrongly, be implemented based on the unscientific Great Barrington Declaration.

There are certain characteristics of some individuals that constitute assets for society and that it is on the benefit of them, that the society should take egoistically advantage of and protect, not because it is a genuine human right of those who possess these characteristics, but because it is a selfish convenience for society and because the health and often the life of a large part of the population depends on the wellbeing of them.

If the Great Barrington Declaration is enforced, the result will be a nash equilibrium in the worst possible of the cases Nash, John Forbes (1950) [31].

We are facing two simultaneous pandemics, one occasioned by SARS-Cov-2 and the other, due to misinformation [1]. Sadly, the Great Barrington's statement sounds extremely reasonable and mostly satisfy all parties, those who prefer to expose themselves, those who desire to protect themselves, the economy, the government, the rulers. Notwithstanding, it has an undeniable rhetorical component, It is a apotheosis of ochlocracy. Sadly, if reachable, it is going to be Nash equilibrium in non-Pareto optimal [31].

As it is historically favorable for this policies to be implemented on appearance rather than based on a strong scientific and legal foundation, we must consider that it is possible that policies derived from the Great Barrington declaration or on any analogous naive proposal, will be generated that are implemented with tragic consequences, not only local, but also global. Even if that ludicrous case results implemented, our proposal would lessen the severity of the tragic consequences.

As a scandalous darwinian instance, the viruses as a subset of parasites, have the tendency, which we anthropomorphically have interpreted as to explode, take over and hijack i.e. abduct the parasitized organisms, allowing parasite to multiply more or less successfully by modifying the behavior of the host and due to, improving the reproductive success of the parasite [32].

Among those who proudly and wrongly believe in evolution, they do not understand it, since they take the dramatically Lamarckian position. The exceptional darwinian who believes in random variation and selection of the best fit, is also wrong, because it is not survival, but reproduction. Applicable to the case is the seductive male of the Mantis religiosa and the fertilizer of the black widow. The bottom concept lies in the selection of the genes, the selfish gene, which is the paradigm of evolution. What are inherited are the genes. What are selected are the genes and not the organisms [33].

We have been subjected to paradigms of International medical educators whom protagorically maintained that in terms of the mathematical theory of games, it is detrimental for the virus to kill or incapacitate the parasitized organism, as this diminishes its multiplication success. It is inappropriate and naïve to consider SARSCov-2 as an enemy. With viruses, there is no possible peace agreement [31].

Deadly, other potential causes of failures of the Great Barrington declaration are that, those who are exposed, become infected and that they will, later infect their protected relatives within their own homes; furthermore, we do not know the duration of immunity or its effectiveness. We doxastically believe, mantain that those who expose themselves without face masks on the street are not very likely to wear face masks in their own homes, or to maintain the appropriate distance, etc., so as not to infect their high-risk relatives. The argument from the Great Barrington Declaration that herd immunity will eventually be achieved is parvularily fallacious, herd immunity for influence, HIV, syphilis, malaria, herpes, tuberculosis, and amebiasis has not been achieved.

We frontally maintain the fact that the Great Barrington Declaration has an evident shortcoming due to the possibility of intrafamilial contagious to fragile people from the infected. With the argument of protecting the elderly, many old persons will be displaced to nursing homes. It is highly unlikely that the working young adult, economical productive population, will decide to live in the cellar to avoid transmitting the infections to the grandparents.

It is known, the genome of SARS-CoV-2 is a single-stranded RNA that is the longest known. It has 30,000 nucleotides, although the great majority of mutations produce a disadvantage for the virus that suffers them, which is the case for any living organism, the rare mutations that accidentally confer advantage are the basis of the Darwinian selection. The duplication of the RNA genome of the SARS Co-2 virus has a very low error rate per reproductive cycle since it possesses the errorcorrecting enzymatic machinery.

The argument expressed in Great Barrington's statement related to lost time of presential education is rhetorical and fallacious, even more, it is the opportunity to make it evident that current classroom 
education is a total failure and not something that should be tried to maintain as a magnum opus. Confinement has allowed us to learn that we have to be selective, it is not a time when we should maintain our right to choose superfluous things or useless services. The misinformation pandemic has potentiated the expansion of the SARSCov-2 Pandemic (Figure 1) [34].

Under Non-commercial License, Copyright $\odot$ International GeoGebra Institute, 2013.

$$
\begin{aligned}
& a: y=2^{x} \\
& \mathrm{~b}: y=4^{x} \\
& c: y=e^{x} \\
& \mathrm{~d}: y=\left(2^{x}\right)\left(4^{x}\right)
\end{aligned}
$$

In this manner, when they are infected, increases the probability that the susceptible will be infected but also increases the size of the inoculum, which increases the probability that if the interlocutor is infected he presents a more severe clinical picture, due to the larger inoculum. Thus, the whatsApp is better than the telephone to prevent and reduce the effect of SARS-Cov-2, because the interlocutors do not talk. Confinement has diminished environmental pollution, led to savings in transportation, a reduction in accidents, fights, alcohol consumption, drugs, and sexual assaults.

The Great Barrington's statement constitutes an ad verecundiam fallacy, since the signatories are not experts in what they propose. It has a democratic tinge, it seems that everyone decides whether to expose or to protect themselves [4]. All of these considerations might apply to future pandemics as well.

Countless world-class experts suffer the fallacy ad verecundiam, inferring on lands that are beyond the area where they are experts. It is an occurrence of the Dunning-Kruger effect [35]. "Unskilled and Unaware of It: How Difficulties in Recognizing One's Own Incompetence Lead to Inflated Self-Assessments."

A shocking instance is evident in the conference a scientist mistakenly conceives it in the Second Lecture in the COVID-19, SARSCoV-2 and the Pandemic Series, presented by the MIT Department

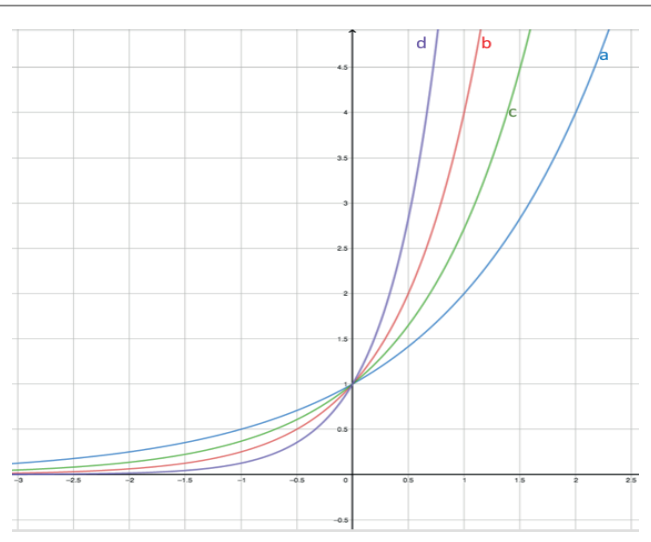

Figure 1: In this graphic, "c" represents the immune response; "b" represents the exponential growth of the virus over wheming the immune response; "a" represents the viral growth with minimal inoculum; " $d$ " represents the potentialized adverse effect of the growth of the virus multiplied by the effect of dysinformation which increases the deviant e irresponsible behavior [34]. of Biology. Britt Glaunsinger of the University of California, Berkeley, when she gave a lecture titled "Coronavirus Biology." She stated: "If you have a genome that is 10,000 bases long, and the polymerase makes an error, on average, 1 in 10,000, you are going to have an error randomly somewhere, every time you copy that RNA, but if you have a longer genome you are going to have more than one error every time you copy that RNA". The right calculation is: The probability of having none errors would be $[36,37]$ :

$$
\left(\frac{9,999}{10000}\right)^{10000}=0.368
$$

The probability of having at least 1 error is:

$$
\mathrm{P}=1-\left(\frac{9,999}{10000}\right)^{10000}=0.632
$$

It is physically unquestionable that if two people have face masks, the probability of contagion is the product of the independent probabilities. If the efficiency of the mask is:

$$
\left(\frac{1}{t}\right)^{2}
$$

If two interlocutors are wearing a mask the protector effect when one is contagious is:

$$
\left(\frac{1}{t}\right)^{2}
$$

Biophysically it is the case that the inoculum decays with the square of the distance between the infective and the susceptible.

Using face masks, if an infective person interacts with a susceptible person, the probability of becoming infected as well as the amount of inoculum decreases, as it is the product of the independent probabilities of the protection that each face mask confers.

Epidemiologically, the probability of contagion increases linearly with the time of exposure. We hypothesize that since children pass more time at a large distance from their peers, they stayed less time in close contact with each other, they spent more time playing outdoors, and probably, due to those causes, the infected children acquire the infection with smaller inoculum than adults. This would be thoroughly compatible with our hypothesis that with less inoculum, we are to expect more subclinical cases and less clinical manifestations with the consequent lesser mortality.

We acknowledge that even though, our recommendations are far from ideal, they could improve almost any policy in confronting the Pandemic. This includes the implementation, against science, of the Great Barrington Declaration. It is evident that our model applies to any present or future epidemic/pandemic.

The epidemiological cost to obtain herd immunity is determined by the lethality. As per November 29, 2020, according to mortality analyses from Coronavirus resource Center of Johns Hopkins University \& Medicine, the number of deaths per 100 confirmed cases (observed case-fatality ratio) the highest in the world is for mexico with $9.6 \%$ and $2.0 \%$ for the United States. This means that grosso modo, if we let the Pandemic grow without bound, we could expect $9.6 \%$ of the Mexican population to die and $2.0 \%$ of the US population to die. So it would be 10 million deaths in Mexico and 6 million in the United States.

In Our World in Data, the case fatality rate for mexico is $10 \%$, while for the USA and for the World is slightly above $2.5 \%$ [37]. Applying 
the logic of the decision, we must distinguish a desideratum from what is physically, economically, legally, and politically implementable. It is a matter of policymaking founded on science and law instead of doxastic logic, based on misinformation and bigotry. It is a matter of policy enforcement by cybernetics, by behavior engineering, not of a recommendation [38].

As the Director-General of the World Health Organization (WHO), Tedros Adhanom Ghebreyesus manifested at the Munich Security Conference: "But we're not just fighting an epidemic; we're fighting an infodemic" $[1,39]$.

It is fundamental to decide whether to protect the vulnerable, versus protecting the best and brightest genius minds of our society, those most transcendent to the World i.e. the clinicians and the researchers, the medical personnel, the epidemiologists, telemedicine and educational communications engineering staff, etc.

Even though everyone has the same rights, each person's contribution to the well-being and health of society is different. The physician and the one who is irresponsibly and voluntarily exposed to SARS-Cov-2 have the same rights; however, the first is a benefactor and the second is a member of the society who has a behavior with potentially adverse consequences for others which is not only inadmissible, but many countries consider a crime to spread an infection knowing that one is sick of a contagious disease.

Furthermore, those who can educate without exposing the students, distance learning, virtual education as is the case of Khan Academy, MITx, Coursera, That Quiz, or at individual producers like us. We have a channel on YouTube: Principia Pedagógica Eléntica Heurística: No school, no teachers! 5,400 scientific lessons. This is more than what an average Bachelor's degree graduate in science or engineering could expect to learn in the best universities of the world [41].

Evidently, there is no gun, no cigarette, no saturated fatty acid, no illicit drug, no torture, no discrimination act, and no education act through punishment that can be considered healthy. In the same way, there is no exotic pet, an exotic meal, hunting of exotic animals, zoophilia that may be accepted as appropriate for health. We maintain that this extends to the fact that domestic animals are not healthy for global health, even if they are perceived as part of the family and if they are considered cute.

The first case of SARS-CoV-2 in mink has been confirmed in Oregon in The United States, res ipsa loquitur [42].

Our invasion of other mammalian habitats and bizarre behavior has been a substantial component of the SARS-Cov-2 and HIV tragedies. We mostly consider Edward Jenner' discoveries [43]:

Extracted from: An inquiry into the causes and effects of the Variolee Vaccince, or Cow-Pox. 1798 Jenner, Edward. The three original publications on vaccination against smallpox [43].

The deviation of man from the state in which he was originally placed by nature seems to have proved to him a prolific source of diseases. I selected a healthy boy, about eight years old, for the purpose of inoculation for the cowpox.

The matter was taken from a sore on the hand of a dairymaid, who was infected by her master's cows, and it was inserted, into the arm of the boy by means of two superficial incisions. On the seventh day, he complained of uneasiness in the axilla, and on the ninth, he became a little chilly, lost his appetite, and had a slight headache. During the whole of this day he was perceptibly indisposed and spent the night with some degree of restlessness, but on the day following he was perfectly well.

In order to ascertain whether the boy was secure from the contagion of the smallpox, he was inoculated with variolous matter, taken from a pustule. Several slight punctures and incisions were made and the matter was carefully inserted, but no disease followed. Several months afterwards he was again inoculated with variolous matter, but no sensible effect was produced on the constitution.

To share our thoughts with the reader: What would our present society do to Jenner if he would have done his experiments today? What do we learn from Jenner's actions? What would we consider pertinent to teach Jenner scientifically and ethically?

Those who want to go out, run the risk of getting infected. Our proposal is the cheapest and simplest. Although it is intuitive to think that the greater the inoculum, the greater the probability of becoming infected, which is fully recognized. However, larger inoculums must progress to more serious clinical pictures which is something that in fact nobody considers.

Not exclusively in this Pandemic, but also in those that will follow in the near future, as these will arrive more and more frequently if we continue to fail to conform with what we demonstrate in this article.

A concept that is fundamental and that is practically never considered is that preventive medicine and healthcare medicine increase the prevalence of many diseases, which is a well-known epidemiological phenomenon and that is also contrary to what the World Health Organization proposes: to seek the greatest bio psychosocial benefit for most of the world. This is an instance of the fallacy of composition. We are not saying that it should not be done; we have demonstrated that the WHO definition must change from an aspirational policy to an achievable result. Thus, "res ipsa loquitur."

A pertinent extract from the Constitution of the World Health [44] Organization states: Health is a state of complete physical, mental, and social well-being and not merely the absence of disease or infirmity. The health of all peoples is fundamental to the attainment of peace and security and is dependent upon the fullest cooperation of individuals and States. The extension to all peoples of the benefits of medical, psychological, and related knowledge is essential to the fullest attainment of health. Governments have a responsibility for the health of their peoples which can be fulfilled only by the provision of adequate health and social measures [44].

According to the mathematical theory of communication of Shannon, in the context of ochlocratic selective processes, in order to be elected at the government or chosen by those elected we consider that here we make evident that we have the scientific knowledge and technology to act and react to tame, not only this pandemic, but those that we will necessarily face. We can respond immunological and epidemiological at a faster growth rate than the pandemic can.

Incorporating, in addition, the so called self-service tools (smart phones and websites) and artificial intelligence robots to reengage, interview, remain, and enforce conditional behavior of the population in order to make people to do what it has to be done, we can reach a new normality that could be better than the old one.

Many authorities and legislators product of the ochlocratic processes are a huge obstacle, as evidenced in two issues, "Confidentiality and Privacy" above health, decision made to optimize political or economic goals rather than scientific ones.

The availability of QR codes, NFC, RFID and URL'S allow us to engage the majority of the population to behave according to the 
cybernetics and behavioral engineering described here. Security and safety can be executed with double authentication, biometrics and Digital Identity Management (DIM) creating a permanent Health Information system for the individual and for the whole population itself, allowing us to have essential data with " $n$ " dimensions in a subset of infinite dimensions of the mathematical universe of Hilbert, precise location, behavioral types, heat maps, that allow us to monitor in a vector field, measure the level of success and warn individuals and communities of the risks and the implications of their actions, exemplified in sending messages to the individuals alarming over the risk of getting infected in a different topographies.

Through the technology of Augmented Reality (AR) we empower the citizens by accessing a link to open the camera in the cellular phone to see the surroundings and AR will pinpoint the people that have died in the proximities, even people that are dyeing can leave a message that can be seen by neighbors, improving the awareness by mean of vicarious behavioral schedule. This can be accomplished using the phone GPS, Nearby Application Program Interfaces and Internet of things (IoT) among other geolocation solutions.

Crowd sourcing is the fastest and most reliable way to get information in real time from the individual and for the individual himself, Waze through GPS support provides turn-by-turn navigation information and user-submitted travel times and route details, while downloading location-dependent information over a mobile telephone network which is free to download and use. It constitutes the most reliable source of traffic, by the person sharing his "life location", his information is used to process the algorithms and show optimal routes and raffic levels. In addition this type of cybernetic solutions can deliver the best results by implementing four basic concepts of a successful platform, capture only once (auto-capture is the most reliable way to capture everybody's own information), at the cloud, with the use of AI, and personal heuristics efficiently implementable at minimum economical and behavioral cost.

The use of "Communication Platform as a Service" (CPaaS) and cloud services are the last link to implement the propositions made in this article. Axiological conclusive desiderata [9]. The guidelines, if they are to be implemented, depend on the application of cybernetics, radical behaviorism, and the behavioral engineering that derives from it.

The inoculum decays with the square of the distance and linearly with the exposure time. If universal mask usage is enforced, whenever two persons, one of whom has been susceptible and the other has been contagious, the protector effect is the product of both of them. Thus, if the mask reduces the amount of virus to $1 / 10$, then when both are wearing them, the reduction is to $1 / 10$ times $1 / 10$, so it is $1 / 100$. These diminish the probability of infection to $1 / 100$, but also, and fundamentally pertinent for our proposition is that, in case of contagious, the inoculum would tend to be $1 / 100$ of what would have been without any mask.

These are the social costs to pay for tame anti-scientific doxastic logic and the Pandemic. The behavior engineering optimization goal is going to be through:

The mandatory universal use of approved mask, do not deal with travelers, do not deal with those who are exposed; that is, with those who do not comply with this list, do not deal with those who have clinical manifestations, do not share cutlery or glasses, cover your mouth when coughing, do not attend weddings or wakes, do not get on busses or planes, pay everything online, do not carry out or tolerate, encourage or allow useless commercial, cultural, entertainment activity; but only the essentials of the market, fewer hairdressers, gyms, etc., no face-to-face activity in schools, businesses, or procedures, do not travel uselessly, permanent and universal instrumentation of cybernetics, radical behaviorism and Bayes' theorem application in every conditional probability decision, recognize the false suffrage ochlocracy. All this translates into a low probability of becoming infected, but also in a low inoculum. Patients with subclinical manifestations release fewer viruses. The greatest distance, the shortest interaction time and no gathering. Continuous use of masks, do not eat together since it is a moment in which we remove the masks, eat alone and isolated, do not go to cinemas, restaurants, bars, do not go out, have all the meetings outdoors, with fewer people, no meetings, wash hands continuously, no shouting, no singing, no talking, no kissing, no touching. Not doing things without epistemological or axiological sense. Make this time an opportunity to learn logic, mathematics, physics, chemistry, biology, physiology, computation science are fields pursuable during the confinement $[6,39]$.

Results in a tragedy and could also be a crime, that the reason to open an unnecessary business is not that they are advantageous for society, but because those who sell the superfluous, need the money and that money will be used to demand other products and services. Economics is an instance of thermodynamics and as such has to be approached [45].

\section{Conflict of Interest}

Nery Lamothe and Mara Lamothe have received official communication from the Mexican Secretaría de Gobernación, Number DACCP-CG/294/19 and dated 29 November 2019, related to the donation of 650 University Lessons to the Government of the Mexican Republic and to become advisors to the President of Mexico in Mathematics and Science. For the aforementioned reasons, this work is dedicated to the Mexican citizens, represented Constitutionally by President Lic. Andrés Manuel López Obrador.

\section{Acknowledgement: “Tabula Gratulatoria”}

Nery Lamothe and Mara Lamothe to Dr. Ernesto Villanueva to whom we are permanently grateful for having rescued our epistemologic, academic, axiological and pedagogical rights in terms of recovering from violations to the $1^{\text {st }}, 3^{\text {rd }}, 6^{\text {th }}, 7^{\text {th }}, 9^{\text {th }}, 14^{\text {th }}$, and $16^{\text {th }}$, articles of the Constitución Política de los Estados Unidos Mexicanos.

The authors acknowledge Dr. Juan Frausto, former Director of the Doctorate Program in Computational Logic at the Instituto Tecnologico y de Estudios Superiores de Monterrey, for his apotheosically pedagogical aportation, who we consider the highest authority in computational logic, stochastic models, Markov chains, modal, doxastic and desiderative logic, all of it applied pervasively thoroughly in this work and has universal applications.

Therefore, we most strongly insist in the recent representative bibliography $[46,47,48,49]$. The Hybrid Forecasting Method SVRESAR for Covid-19; GRSA Enhanced for Protein Folding Problem in the Case of Peptides; Forecasting Oil Production Time Series With a Population-Based Simulated Annealing Method; Markov Decision Processes for Infinite Horizon Problems Solved with the Cosine Simplex Method. The first use forecasting methods for Covid and uses stochastic algorithms and Machine learning.

The second is about a new forecasting method that Boltzamn uses with simulated Annealing. The challenge there is threefold, on the one hand, to detect incorrect information that occurs frequently in many cases (it also happens in Covid), the second is to estimate the information that could have been correct, and third, to accurately 
forecast data present with information in an instanced case of energy resources.

The third article is a novel method of Markov decision processes to solve decision problems of a private or governmental entity. In this case, policies are sets of actions that the decision-maker must apply to obtain the optimal result, not only now but within a certain period.

\section{References}

1. Cox RM, Wolf JD, Plemper RK (2020) Therapeutically Administered Ribonucleoside Analogue MK-4482/EIDD-2801 Blocks SARS-CoV-2 Transmission in Ferrets. Nat Microbiol 6: 11-18.

2. Skinner BF (1974) About Behaviorism. Vintage Books, USA.

3. Aristoteles (1987) Tratados de Lógica. Editorial Porrúa, México.

4. Lamothe PJ (2007) Reforma de los Estados Democráticos y de los Oclócratas. México: Primer Mandante Epistemócrata de los Estados Unidos Mexicanos.

5. Wiener N (1961) Cybernetics or Control and Communication in the Animal and the Machine, MIT.

6. Bayes T (1763) An Essay Towards Solving a Problem in the Doctrine of Chances. By the late Rev. Mr. Bayes, F. R. S. communicated by Mr. Price, in a letter to John Canton, A. M. F. R. S. Philosophical Transactions of the Royal Society of London 53: 370-418.

7. Jameson JL, Fauci AS, Kasper DL, Hauser SL, Longo DL, et al. (2015) Harrison's Principles of Internal Medicine $19^{\text {th }}$ Ed. McGraw-Hill Education USA.

8. Kermack WO, McKendrick AG (1927) A Contribution to the Mathematical Theory of Epidemics. Roya Society.

9. Lamothe N, Lamothe M, Lamothe D, Lamothe P (2020) Application of the Parsimony Principle of Exponential Functions to the Production of COVID-19 Immunity, According to Bayesian Theorem and Cybernetics, to Tame Anti-scientific Doxastic Logic and the Pandemic. Glo J Biol Med.

10. Gandhi M, Rutherford GW (2020) Facial Masking for Covid-19 Potential for "Variolation" as We Await a Vaccine. N Engl J Med 383: e101.

11. Herman IP (2007) Physics of the Human Body. springer.

12. Lamothe $P$ (1998) Epistemocracia: Primer Tratado General de Ingeniería Política (Spanish Edition).

13. Severe Covid-19 GWAS Group, Ellinghaus D, Degenhardt F, Bujanda L, Buti M, et al. (2020) Genomewide Association Study of Severe Covid-19 with Respiratory Failure. N Engl J Med 383: 1522-1534.

14. World Health Organization (2018) Polio eradication.

15. Corona virus Resource Center (2020) by Johns Hopkins University \& Medicine

16. Bartlett AA (2020) Exponential Growth Arithmetic, Population and Energy.

17. Lamothe N, Lamothe M (2020) COVID-19. El Presidente Tiene que Enseñarle a los Mexicanos a Contar con los Dedos. Principia Pedagógica Eléntica Heurística.

18. Lamothe N, Lamothe M (2020) Modelo Crecimiento Exponencial Población, Introducción. Principia Pedagógica Eléntica Heurística.

19. Lamothe N, Lamothe M (2020) Ecuación Logística, Crecimiento Poblacional. Principia Pedagógica Eléntica Heurística.

20. Lamothe N, Lamothe M (2020) Ecuación Logística, Límite Cuando el Tiempo Tiende a Infinito. Crecimiento Población. Principia Pedagógica Eléntica Heurística.
21. Lamothe N, Lamothe M (2020) Para Entender la Pandemia del COVID-19 Hay que Estar Preparados. Ecuación Logística. Principia Pedagógica Eléntica Heurística.

22. Lamothe N, Lamothe M (2014) Área Ocupada por Lirios en una Laguna, Problema (1/3). Función Exponencial. Principia Pedagógica Eléntica Heurística.

23. Lamothe N, Lamothe $M$ (2014) Área Ocupada por Lirios en una Laguna, Problema (2/3). Función Exponencial. Principia Pedagógica Eléntica Heurística.

24. Lamothe N, Lamothe M (2014) Área Ocupada por Lirios en una Lagunaj, Problema (3/3). Función Exponencial. Principia Pedagógica Eléntica Heurística.

25. Perkowitz S (2010) Gedankenexperiment. Encyclopædia Britannica.

26. Noël N, Saez-Cirion A, Avettand-Fenoël V, Boufassa F, Lambotte $O$ (2019) HIV Controllers: to Treat or Not to treat? Is that the Tight Question? Lancet HIV 6: E878-E884.

27. Gandhi M, Beyrer C, Goosby E (2020) Masks Do More Than Protect Others During COVID-19: Reducing the Inoculum of SARS-CoV-2 to Protect the Wearer. J Gen Intern Med 35: 3063-3066.

28. Handel A, Li Y, McKay B, Pawelek KA, Zarnitsyna V, et al. (2018) Exploring the Impact of Inoculum Dose on Host Immunity and Morbidity to Inform Model-Based Vaccine Design. PLoS Comput Biol 14: e1006505.

29. Kulldorff M, Gupta S, Bhattacharya J, Walker A, Kavaliunas A (2020) The Great Barrington Declaration.

30. Alexanderson K, Althaus CL, Alwan N, Burgess RA, Bear A (2020) The John Snow Memorandum.

31. Nash JF (1950) The Bargaining Problem. Econometrica 18: 155-162.

32. Burt A, Trivers R (2006) Genes in Conflict. Belknap Harvard, USA.

33. Dawkins R (1982) The Extended Phenotype. Great Britain, Oxford.

34. Barreda S, Asadi S, Cappa CD, Wexler AS, Bouvier NM, et al. (2020) The Impact of Vocalization Loudness on COVID-19 Transmission in Indoor Spaces. Quantitative Biol.

35. Kruger J, Dunning D (1999) Unskilled and Unaware of it: How Difficulties in Recognizing one's own Incompetence Lead to Inflated Self-assessments. J Pers Soc Psychol 77: 1121-1134.

36. Glaunsinger B (2020) Lecture 2: "Coronavirus biology." MIT Department of Biology.

37. Jaynes ET (2003) Probability Theory the Logic of Science. The press Syndicate of the University of Cambridge, United Kingdom.

38. Ritchie H, Ortiz-Ospina E, Beltekian D, Mathieu E, Hasell J, et al. (2020) Mortality Risk of COVID-19. Our world data, USA.

39. Jeffrey R C (1965) The Logic of Decision ( $2^{\text {nd }}$ ed). The University of Chicago Press Books.

40. Adhanom T (2020) Munich Security Conference. World Health Organization.

41. Lamothe N, Lamothe M (2020) Principia Pedagógica Eléntica Heurística.

42. Oregon Department of Agriculture (2020) First case of SARS-CoV-2 in mink confirmed in Oregon.

43. Jenner E (2001) The Three Original Publications on Vaccination Against Smallpox. Harvard Classics 38: 1909-1914.

44. World Health Organization (2020) Constitution of the World Health Organization (49 $9^{\text {th }}$ Ed), USA. 
45. Georgescu-Roegen N (1975) Energy and Economic Myths. Southern Economic J 41: 347-381.

46. Solis JF, Vazquez JEO, Barbosa JJG, Valdez JC, Hernández JPS (2020) The Hybrid Forecasting Method SVR-ESAR for Covid-19. Int Combinatorial Optim Probl Inform.

47. Frausto-Solís J, Sánchez-Hernández JP, Maldonado-Nava FG, González-Barbosa JJ (2019) GRSA Enhanced for Protein Folding Problem in the Case of Peptides. Axioms 8: 136.

48. Frausto-Solís J, Chi-Chim M, Sheremetov L (2015) Forecasting Oil Production Time Series with a Population-Based Simulated Annealing Method. Arabian J Sci Engin 40: 1081-1096.
49. Frausto-Solis J, Santiago E (2010) Markov Decision Processes for Infinite Horizon Problems Solved with the Cosine Simplex Method. J Math Progr Oper Res 61: 1133-1150.

50. Frausto-Solis J, Hernández-Ramírez L, Castilla-Valdez G, GonzálezBarbosa JJ, Sánchez-Hernández JP (2021) Chaotic Multi-Objective Simulated Annealing and Threshold Accepting for Job Shop Scheduling Problem. Math Comput Appl 1: 8. 